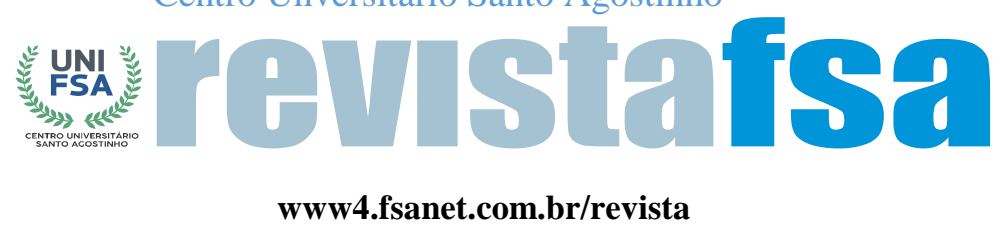

Rev. FSA, Teresina, v. 18, n. 6, art. 4, p. 77-95, jun. 2021

ISSN Impresso: 1806-6356 ISSN Eletrônico: 2317-2983

http://dx.doi.org/10.12819/2021.18.6.4

\title{
A Nova Contabilidade Pública Brasileira e Sua Aplicação em uma Instituição Federal de Ensino Superior do Rio de Janeiro
}

\section{The New Brazilian Public Accounting and its Application in a Federal Higher Education Institution in Rio de Janeiro}

Claudio Luiz de Oliveira Costa

Mestre em Administração pela Universidade Federal Fluminense Administrador na Universidade Federal Fluminense

E-mail: claudioluizoc@gmail.com

Diego de Oliveira da Cunha

Doutorado em Engenharia de Produção e Sistemas pelo Cefet RJ Mestre em Administração pela Universidade do Grande Rio

Professor do Ensino Básico, Técnico e Tecnológico no Instituto Federal do Mato Grosso

E-mail: diego.cunha@aluno.cefet-rj.br

Gabriel Alexandre de Oliveira Costa

Graduado em Ciências Contábeis pela Universidade Federal Fluminense

E-mail: gabrielaoc1991@gmail.com

Carlos Alberto Schettini Pinto

Doutorando em Engenharia de Produção e Sistemas pelo Cefet RJ

Mestre em Engenharia de Produção e Sistemas pelo Cefet RJ Professor da FGV Online

E-mail: carlos.schettini@aluno.cefet-rj.br

Clayton Pereira Gonçalves

Doutor em Administração pela Universidade do Grande Rio Professor da Universidade Federal de Rondônia

E-mail: clayton.goncalves@unir.br

Endereço: Claudio Luiz de Oliveira Costa

Universidade Federal Fluminense (COLUNI) - Rua Alexandre Moura, 8 - São Domingos. CEP: 24210-200, Niterói/RJ, Brasil.

Endereço: Diego de Oliveira da Cunha

(CEFET/RJ) - R. Gen. Canabarro, 485 - Maracanã. CEP: 20271-204, Rio de Janeiro/RJ, Brasil.

Endereço: Gabriel Alexandre de Oliveira Costa

Universidade Federal Fluminense (COLUNI) - Rua

Alexandre Moura, 8 - São Domingos. CEP: 24210-200,

Niterói/RJ, Brasil.

Endereço: Carlos Alberto Schettini Pinto

(CEFET/RJ) - R. Gen. Canabarro, 485 - Maracanã. CEP: 20271-204, Rio de Janeiro/RJ, Brasil.

Endereço: Clayton Pereira Gonçalves

(UNIR) - Av. 02 - Rotary Clube, Setor 10, Quadra 01,

Lote único 3756 - Jardim Social. CEP: 78995-000,

Vilhena - RO, Brasil.

Editor-Chefe: Dr. Tonny Kerley de Alencar Rodrigues

Artigo recebido em 21/02/2021. Última versão recebida em 12/03/2021. Aprovado em 13/03/2021.

Avaliado pelo sistema Triple Review: a) Desk Review pelo Editor-Chefe; e b) Double Blind Review (avaliação cega por dois avaliadores da área).

Revisão: Gramatical, Normativa e de Formatação 


\title{
RESUMO
}

O objetivo dessa pesquisa é verificar e analisar o grau de adoção do procedimento de depreciação na Universidade Federal Fluminense (UFF) e apontar as principais barreiras encontradas na adoção do procedimento de cálculo da depreciação. A metodologia utilizada foi a pesquisa bibliográfica. Além disso, utilizou-se a pesquisa descritiva, pois descreve as características dos respondentes (contadores, técnicos de contabilidade e agentes patrimoniais) quando ligadas ao conhecimento da legislação aplicada à Contabilidade Pública referente à depreciação na Instituição Federal de Ensino Superior (IFES). Portanto, os dados que compõem a pesquisa foram coletados por meio da aplicação de questionário, tabulados na planilha Microsoft Excel e analisados à luz da estatística descritiva. Os resultados a respeito da NBC TSP apontam que $11,1 \%$ não sabem se a UFF adota o procedimento de depreciação requerido pela norma, $85,2 \%$ nem sabiam que a norma existia e apenas 3,7 afirmaram que a conhecem e a aplicam. Ademais, foi possível notar que a IFES não promoveu qualquer tipo de treinamento para qualificar seus servidores sobre este assunto. Além disso, ficou evidente que quando se trata da dificuldade de calcular a depreciação a maioria dos participantes afirmou que a falta de informações precisas a respeito dos bens e de encontrar o valor depreciável estão entre os maiores problemas. Conclui-se que a IFES, quanto ao assunto depreciação, para prestar um melhor serviço de controle, qualidade e transparência, necessita investir em treinamento, adquirir softwares capazes de armazenar e disponibilizar informações a respeito dos ativos imobilizados e, finalmente, compartilhar essas informações para todos os Setores da Universidade.

Palavras-chave: Contabilidade Pública. Depreciação. Patrimônio Público.

\begin{abstract}
The objective of this research is to verify and analyze the degree of adoption of the depreciation procedure at the Federal Fluminense University (UFF) and to point out the main barriers found in the adoption of the depreciation calculation procedure. The methodology used was bibliographic research. In addition, descriptive research was used, as it describes the characteristics of the respondents (accountants, accounting technicians and estate agents) when linked to the knowledge of the legislation applied to Public Accounting related to depreciation in the Federal Institution of Higher Education (IFES). Therefore, the data that compose the research were collected through the application of a questionnaire, tabulated in the Microsoft Excel spreadsheet and analyzed under the light of descriptive statistics. The results regarding the NBC TSP show that $11.1 \%$ do not know if UFF adopts the depreciation procedure required by the standard, $85.2 \%$ do not even know that the standard existed and only 3.7 stated that they know and apply it. In addition, it was noted that IFES did not provide any training to qualify its employees on this subject. Furthermore, it was evident that when it comes to the difficulty of calculating depreciation, most participants stated that the lack of accurate information about assets and finding depreciable value are among the biggest problems. It is concluded that IFES, in relation to depreciation, to provide a better service of control, quality and transparency, needs to invest in training, acquire software capable of storing and making available information regarding fixed assets and, finally, sharing this information for all University Sectors.
\end{abstract}

Keywords: Public Accounting. Depreciation. Public Heritage. 


\section{INTRODUÇÃO}

A Contabilidade Pública brasileira vem passando por um processo de mudanças no decorrer dos últimos anos para melhor atender às entidades, aos profissionais e ao público interessado nas demonstrações contábeis. Nesse contexto, diante de uma economia cada vez mais globalizada e da crescente cobrança por informações, faz-se necessária a convergência da Contabilidade brasileira aos padrões internacionais para tornar as demonstrações contábeis mais transparentes, relevantes e comparáveis. Devido às peculiaridades nacionais, este importante processo de harmonização dos procedimentos e técnicas contábeis visa adaptar as leis e normas brasileiras às normas internacionais. Para Rosa (2011, p. 01), "a harmonização deve ser feita, em primeiro lugar, internamente, mediante redução das diferenças das normas contábeis internas e padronização dos procedimentos, técnicas e políticas contábeis".

Diante deste cenário, por meio da portaria n ${ }^{\circ}$ 184/08, o Ministério da Fazenda decidiu dar início ao processo de convergência da Contabilidade Pública brasileira às Normas Internacionais de Contabilidade aplicadas ao Setor Público ou International Public Sector Accounting Standards (IPSAS), editadas pela Federação Internacional de Contabilidade, também conhecida como Internacional Federation of Accountants (IFAC). Desse modo, em seu art. $1^{\circ}$, a portaria determina que a Secretaria do Tesouro Nacional (STN), órgão central do Sistema de Contabilidade Federal, deve promover ações no sentido de convergir as IPSAS publicadas pelo IFAC às Normas Brasileiras de Contabilidade aplicadas ao Setor Público (NBCASP), publicadas pelo Conselho Federal de Contabilidade (CFC).

Além disso, em 2008, o CFC publicou, por meio das resoluções CFC 1128/08 a 1137/08, as primeiras dez Normas de Contabilidade aplicadas ao Setor Público com objetivo de promover o reconhecimento, mensuração e evidenciação dos atos e fatos praticados pelos agentes públicos. Dentre essas normas se encontra a NBC T16.9, que define critérios e procedimentos para o cálculo e registro da depreciação, amortização e exaustão. Posteriormente, no ano de 2011, o CFC, por meio da resolução 1366/11, publicou sua $11^{\text {a }}$ norma, a NBC T16.11.

Em 28 de setembro de 2017, o CFC publicou por meio do Diário Oficial da União (DOU) a NBC aplicada ao Setor Público, NBC TSP 07, referente ao tratamento contábil dos ativos imobilizados. A nova norma que tem por referência a IPSAS 17 passou a ser vigente em 01/01/2019 e substituiu a antiga NBC T16.9. Portanto, a NBC TSP 07 conceitua a depreciação como a alocação sistemática do valor depreciável de ativo ao longo da sua vida 
útil e estabelece que os métodos para cálculo da depreciação devem ser o linear, o dos saldos decrescentes e o das unidades produzidas.

Sendo assim, a adoção do processo de mensuração e reconhecimento da depreciação pelas entidades do setor público demonstra a mudança de foco que se deu nos últimos anos. Essa transformação, além de tornar as informações contábeis mais completas e propícias à análise, também evidencia maior transparência por parte dos gestores e entidades.

Neste contexto, o presente artigo visa responder ao seguinte problema de pesquisa, a saber: até que ponto o procedimento de depreciação, conforme previsto pela NBC TSP 07, tem sido aplicado pela Universidade Federal Fluminense (UFF)?

No tocante ao objetivo geral, este artigo busca verificar e analisar o grau de adoção do procedimento de depreciação na UFF, até o mês de julho de 2019. Para que se alcance este objetivo geral, é necessário que sejam alcançados os seguintes objetivos específicos, a saber: descrever a depreciação e suas características a fim de demonstrar sua relevância na área pública e apontar os principais óbices encontrados na adoção do procedimento de cálculo da depreciação na referida IFES.

Diante do exposto, o presente trabalho se justifica por tratar-se de uma norma extremamente importante e recente na Contabilidade Pública e por verificar e analisar o grau de adoção do procedimento de depreciação em uma IFES, sediada no Estado do Rio de Janeiro, bem como das dificuldades encontradas na sua aplicação. Além disso, com as recentes mudanças na Contabilidade que implicaram a mensuração e reconhecimento da depreciação por parte dos entes públicos tornam as informações contábeis ainda mais úteis à análise e ao processo decisório. Por fim, a Contabilidade aplicada no setor público é de suma importância para o controle e execução do orçamento, geração de informação e para a tomada de decisão. Nesse sentido, é ela quem subsidia a tomada de decisão do gestor público. Assim, diante da crescente cobrança pelo controle de gastos públicos e por informações úteis, transparentes, comparáveis por parte de contadores, auditores, governos e sociedade, a informação contábil nunca foi tão requisitada.

\section{REFERENCIAL TEÓRICO}

\subsection{A Contabilidade Pública e a Convergência às IPSAS}

A Contabilidade pode ser conceituada como a ciência que por meio de técnicas, normas e princípios registra e controla toda atividade econômico-financeira de uma entidade. 
Dessa maneira, a Contabilidade tem como objetivo o controle do patrimônio de uma entidade e, por isso, seu objeto é o patrimônio. De acordo com Herrmann (1972, p. 58):

Contabilidade é a ciência que estuda o patrimônio à disposição das aziendas, em seus aspectos estáticos e em suas variações, para enunciar, por meio de fórmulas racionalmente deduzidas, os efeitos da administração sobre a formação e a distribuição dos réditos.

Em complementação a este pensamento, Iudícibus et al. (1995, p. 21) afirmam que "o objetivo básico da Contabilidade se resume no fornecimento de informações econômicas para os vários usuários, de forma que propiciem decisões racionais".

A Contabilidade Pública ou Governamental é uma das muitas ramificações que a Ciência Contábil possui, sendo a Contabilidade aplicada ao Setor Público o ramo responsável pelo controle e execução do orçamento. Silva (2014, p. 01) define a Contabilidade Pública como

o "ramo da Contabilidade que coleta, registra e controla os atos e fatos da Fazenda Pública, mostra o patrimônio público e suas variações, bem como acompanha e demonstra a execução do orçamento".

Ainda, segundo Silva (2014, p. 01), “a Contabilidade Pública, além de registrar todos os fatos contábeis, preocupa-se com os atos praticados pelo gestor público, pois estes podem alterar o patrimônio em seus aspectos quantitativos e qualitativos".

Dessa forma, foi por meio da Lei 4.320, criada em 17 de março de 1964, que foram estabelecidas as normas de Direito Financeiro para elaboração e controle dos orçamentos e balanços da União, do Distrito Federal, dos Estados e dos Municípios, o que representou um grande avanço para o controle e execução do orçamento brasileiro. Nesse sentido, Mota (2009, p. 222) afirma que:

Essa lei estabelece muitos dos procedimentos e funções que são exercidas pela Contabilidade pública. Não basta conhecer os princípios e técnicas contábeis profundamente, faz-se mister também ter a compreensão das determinações contidas na legislação relativa à Administração Pública.

Portanto, a Contabilidade aplicada ao Setor Público (CASP), seja em qual for o ente da federação, durante muito tempo teve como foco o controle e a execução do orçamento, deixando de lado seu objeto que é o patrimônio. Segundo o Manual de Contabilidade Aplicada ao Setor Público (MCASP): 
[...] o orçamento público ganhou significativa importância no Brasil. Como consequência, as normas relativas a registros e demonstrações contábeis, vigentes até hoje, acabaram por dar enfoque, sobretudo aos conceitos orçamentários, em detrimento da evidenciação dos aspectos patrimoniais (2019, p. 18).

Desse modo, foi devido às transformações ocorridas nos últimos anos no cenário econômico mundial e na acelerada globalização que o Ministério da Fazenda (MF), em 2008, lançou a portaria $\mathrm{n}^{\circ} 184$ com o objetivo de adequar a Contabilidade Pública brasileira às Normas Internacionais de Contabilidade aplicadas ao Setor Público. Para tornar realidade essa convergência, o MF determinou que a Secretaria do Tesouro Nacional (STN) adotasse os procedimentos citados na portaria $\mathrm{n}^{\circ} 184 / 2008$, conforme descrito a seguir:

I. Identificar as necessidades de convergência às normas internacionais de contabilidade publicadas pela IFAC e às normas Brasileiras editadas pelo CFC;

II. Editar normativos, manuais, instruções de procedimentos contábeis e Plano de Contas Nacional, objetivando a elaboração e publicação de demonstrações contábeis consolidadas, em consonância com os pronunciamentos da IFAC e com as normas do Conselho Federal de Contabilidade, aplicadas ao setor público;

III. Adotar os procedimentos necessários para atingir os objetivos de convergência estabelecido no âmbito do Comitê Gestor da Convergência no Brasil, instituído pela Resolução CFC n ${ }^{\circ} 1.103$, de 28 de setembro de 2007.

Art. $2^{\circ}$ A Secretaria do Tesouro Nacional promoverá o acompanhamento continuo das normas contábeis aplicadas ao setor público editadas pela IFAC e pelo Conselho Federal de Contabilidade, de modo a garantir que os Princípios Fundamentais de Contabilidade sejam respeitados no âmbito do setor público.

Seguindo o que foi determinado pela portaria ${ }^{\circ} 184$, anualmente a STN edita o MCASP para nortear o trabalho dos contadores públicos em relação às normas editadas pelo CFC. Atualmente o MCASP se encontra na $8^{a}$ edição, que contempla em sua segunda parte denominada de Procedimentos Contábeis Patrimoniais, a mais recente NBC aplicada ao setor público que trata dos ativos imobilizados, a NBC TSP 07 e, por sua vez, a depreciação que é o objeto da presente pesquisa.

\subsection{O Patrimônio das Entidades Públicas}

O patrimônio representa o objeto da Contabilidade seja em qual for o ramo a que se aplica. Entende-se, de uma forma mais superficial, o patrimônio como o conjunto de bens, direitos e obrigação pertencentes a uma pessoa física ou jurídica. Kohama (2006, p. 173) define o patrimônio da Contabilidade Pública como o "[...] o conjunto de bens, direitos e 
obrigações avaliáveis em moeda corrente, das entidades que compõem a Administração Pública".

Por outra perspectiva, Bezerra Filho (2006, p. 150) entende que "o patrimônio do Estado constitui o conjunto de bens, valores, créditos e obrigações de conteúdo econômico e avaliáveis em moeda, que a Fazenda Pública possui e utiliza na consecução dos seus objetivos".

Além disso, o patrimônio das entidades públicas pode ser analisado sob dois aspectos, a saber: qualitativos e quantitativos (BEZERRA FILHO, 2006, p. 150). O aspecto qualitativo se refere aos componentes que integram o patrimônio e que auxiliam as entidades a alcançarem seus objetivos sem levar em consideração o valor monetário e se classificam em bens de uso comum, bens de uso especial e bens dominiais. A Lei $n^{0} 10.406$ que trata do Código Civil Brasileiro, em seu art. 98, define os bens públicos como sendo:

\footnotetext{
Os de uso comum do povo, tais como rios, mares, estradas, ruas e praças; Os de uso especial, tais como edifícios ou terrenos destinados a serviço ou estabelecimento da administração federal, estadual, territorial ou municipal, inclusive os de suas autarquias;

Os dominicais, que constituem o patrimônio das pessoas jurídicas de direito público, como objeto de direito pessoal, ou real, de cada uma dessas entidades.
}

Portanto, os bens de uso comum são aqueles sob o domínio público e que não são apropriados ao patrimônio estatal, sendo eles naturais ou artificiais. Os naturais constituem as praias, rios etc. Já os artificiais representam a ação do homem, como ruas, estradas etc. Embora não estejam no ativo da entidade, as obrigações decorrentes desses bens integram o passivo. Assim sendo, para a Contabilidade os bens naturais possuem as seguintes características: não são contabilizados, não são inventariados/avaliados, não podem ser alienados/penhorados e seu uso pode ser gratuito ou oneroso (COSTA et al., 2020a; COSTA et al. 2020b).

No tocante aos bens de uso especial, eles são destinados à manutenção das entidades públicas, sendo eles os móveis e utensílios, os veículos, os prédios, os terrenos urbanos etc. Além disso, eles possuem as seguintes características: são contabilizados, são inventariados e avaliados, são inalienáveis/penhoráveis e estão incluídos no patrimônio (CUNHA; SEVERIANO JUNIOR, 2018).

Por fim, os bens dominiais, embora constituam parte do patrimônio estatal, ainda não tiveram nenhuma destinação/alienação. Como exemplo, há os prédios desativados. Como 
características são contabilizados, são inventariados/avaliados, são alienáveis e podem/geram renda.

A respeito do aspecto quantitativo, pode ser entendido como um agrupamento dos valores do patrimônio, sendo eles o Ativo, o Passivo e o Patrimônio líquido. Para a Contabilidade, o Ativo é constituído de bens e direitos das entidades. Bezerra Filho (2006, p. 155), conceitua o ativo como sendo o:

\footnotetext{
Conjunto dos elementos representativos das aplicações de recursos orçamentários e extraorçamentários, ou seja, constitui os bens e direitos da entidade. Possuem três características: são de propriedade da entidade; mensuráveis em moeda corrente; capazes de gerar benefícios futuros.
}

Por outro lado, o Passivo é o conjunto de elementos que representam obrigações da entidade com terceiros, possuindo as seguintes características, a saber: são de obrigação da entidade adquiridas no passado, são mensuráveis em moeda corrente e podem gerar um desembolso no futuro.

Finalmente, o Patrimônio representa a diferença entra o Ativo e o Passivo e pode apresentar o seguinte resultado: ativo líquido, quando o ativo é maior que o passivo; passivo a descoberto, se o passivo for maior que o ativo; nulo, quando o ativo é igual ao passivo.

\subsection{A Depreciação no Setor Público}

O ativo imobilizado representa um grupo de itens que são classificados como móveis e imóveis. Esses itens auxiliam as entidades a realizarem suas atividades diárias. Ademais, o ativo imobilizado representa um item que "é mantido para o uso na produção ou fornecimento de bens ou serviços, para aluguel a terceiros, ou para fins administrativos; e se espera utilizar por mais de um período contábil" (NBC TSP07, 2017, p. 4). Devido ao desgaste gerado pelo uso contínuo, por ação da natureza ou pelo fato de o bem se tornar ultrapassado tecnologicamente, é que se aplica a depreciação.

Sendo assim, a depreciação representa a redução do valor de um ativo imobilizado. Marion (1988, p. 176) entende que "os bens do imobilizado, com o passar do tempo, em virtude do uso, vão sofrendo deterioração física, perdendo sua eficiência funcional. Esse desgaste ocorrido no período é contabilizado como despesa com depreciação". Para Souza (2016, p. 223): 


\begin{abstract}
A depreciação do ativo se inicia quando este está disponível para uso, ou seja, quando está no local e em condição de funcionamento na forma pretendida pela administração e deve cessar na data em que o ativo é classificado como mantido para venda ou, ainda, na data em que o ativo é baixado, o que ocorrer primeiro.
\end{abstract}

Em relação às retenções, em 21 de novembro de 2008 entrou em vigor a Norma Brasileira de Contabilidade Técnica 16.9 - Depreciação, Amortização e Exaustão, de forma facultativa a partir de sua publicação, mas obrigatória a partir de $1^{\text {a }}$ de janeiro de 2010 . A referida norma visava dar tratamento aos ativos imobilizados, estabelecendo critérios e procedimentos para o registro contábil da depreciação. Consequentemente, a Resolução CFC $\mathrm{n}^{\circ}$ 1136/08 retrata que esta norma estabelece critérios e procedimentos para o registro contábil da depreciação, da amortização e da exaustão.

Porém, devido ao contínuo processo de convergência e adaptação das NBCASP às IPSAS, em $1^{\text {a }}$ de janeiro de 2019 entrou em vigor a nova NBC aplicada ao Setor Público, a NBC TSP07 Ativo Imobilizado, que substituiu a norma anterior, NBC T09, que tratava de depreciação, amortização e exaustão, tendo como referência a IPSAS 17, editada pela The International Public Sector Accounting Standards Board (IPSASB) ou Conselho Internacional de Normas Contábeis do Setor Público.

\title{
2.3.1 Os Métodos para o Cálculo da Depreciação
}

De acordo com o MCASP e a NBC TSP 07, o método de depreciação deve refletir o padrão em que os benefícios econômicos futuros ou potencial de serviços do ativo devem ser consumidos pela entidade. Ainda, de acordo com NBC TSP 07, vários métodos de depreciação podem ser aplicados para calcular o valor da depreciação, tais como o método linear, o método dos saldos decrescentes e o método de unidades produzidas.

De acordo com Iudícibus et al. (2010, p. 250), "calcular a depreciação de ativos imobilizados nem sempre é uma tarefa fácil, pois existem dificuldades, a saber: primeira: estimação da vida útil e segunda: escolha do método".

A respeito da vida, ela depende de duas causas: físicas e funcionais. A primeira se dá devido à utilização do ativo, ou seja, desgaste natural ou ação da natureza. A segunda causa diz respeito ao obsoletismo, ou seja, quando o ativo se torna ultrapassado tecnologicamente. De acordo com Iudícibus e. al. (2010, p. 250), "essas causas atuam sempre em conjunto, de maneira que é difícil, senão impossível, separar os efeitos de cada uma delas". 
Além disso, segundo o próprio Iudícibus et al. (2010, p. 250), “quando não havia progresso tecnológico tão acentuado as causas físicas eram as únicas determinantes da vida útil dos objetos. Mediante um estudo estatístico, a vida útil era estimada com alguma precisão".

A respeito dos métodos de depreciação adotados pela Contabilidade, existem o método das quotas constantes, o método dos saldos decrescentes e o método das unidades produzidas. $\mathrm{O}$ método das quotas constantes é aquele que distribui o custo do ativo em função do tempo. Por causa da sua simplicidade, esta fórmula é vastamente utilizada. A figura 1 apresenta a fórmula para o cálculo dos métodos das quotas constantes.

\section{Figura 1 - Método das quotas constantes}

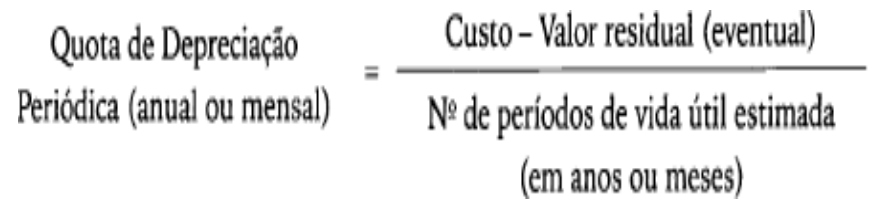

Fonte: Iudícibus et al. (2010, p. 251).

O método dos saldos decrescentes consiste em multiplicar um percentual fixo sobre o valor contábil que vai diminuindo no decorrer dos anos. Esse método possui como vantagem fiscal o fato de que, como as primeiras quotas são maiores, logo o imposto a ser pago será menor, em compensação ao final da vida útil do ativo o contrário ocorre. Ademais, a vantagem desse método é que a maioria dos bens necessita de manutenção e reparo, porém isso é mais suscetível quando os bens se tornam mais velhos. Entretanto, o aumento de despesas com manutenção é compensado pela diminuição do valor de depreciação. A figura 2 apresenta a fórmula para o cálculo do método dos saldos decrescentes.

\section{Figura 2 - Método dos saldos decrescentes}

$$
\text { Percentual anual }=1-\sqrt[1]{\frac{\text { Valor residual }}{\text { Custo do bem }}}
$$

Fonte: Iudícibus et al. (2010, p. 253).

O método das unidades produzidas estima que uma determinada máquina possa produzir um número x de unidades e, conforme este ativo é utilizado, é gerado o valor de depreciação 
e, com isso, a diminuição da vida útil do bem. Por outro lado, caso não haja produção, a vida útil permanece estática.

Figura 3 - Método das unidades produzidas

\section{Quotade Depreciação $=$ Número de unidades produzidas no periodo x 100}

\section{No de unidades estimadas a serem produzidas durante avida útil do bem}

Fonte: Iudícibus et al. (2010, p. 252).

É possível observar que dentre os três métodos mencionados pela NBC TSP 07, o método das quotas constantes é o mais simples, fácil de ser aplicado e analisado, pois a quota de depreciação assim como a taxa em todos os períodos é imutável, a não ser que o valor residual sofra alteração.

A respeito do segundo método, ele apresenta um grau de dificuldade mais acentuado, pois o cálculo é realizado por meio da fórmula que exige um valor residual. Embora a taxa aplicada sobre o valor depreciável seja constante tanto no método dos saldos decrescentes como no método das quotas constantes, é possível notar que o valor da depreciação não é constante como no primeiro método, mas decrescente.

Por fim, o terceiro e último método, o das unidades produzidas, muito utilizado na área industrial, possui fácil aplicação e análise, contudo, diferente dos demais métodos, tem sua vida útil estimada no total de unidades que o equipamento poderá produzir.

\section{METODOLOGIA}

Esta seção procura explicar como a pesquisa foi desenvolvida e que meios foram utilizados para alcançar os resultados. Portanto, a pesquisa foi dividida em dois critérios: quantos aos fins e quanto aos meios.

Quanto aos fins, o presente trabalho utilizou de pesquisa descritiva, porque teve o objetivo de verificar e de analisar o grau de adoção do procedimento de depreciação na UFF. Quanto aos meios, a pesquisa é classificada como bibliográfica, porque foram utilizados livros, artigos e legislações na revisão de literatura.

Além disso, utilizou-se, como instrumento de coleta de dados, um questionário elaborado pelos próprios autores a respeito da depreciação de acordo com a NBC TSP 07 aplicada ao Setor Público que, como visto, trata dos ativos imobilizados. Como são poucas as 
IFES no Estado do Rio de Janeiro, foi escolhida a UFF por se tratar de fácil acesso e facilidade de contato com os pesquisadores.

Desse modo, o questionário foi aplicado de forma anônima para preservar a identidade dos servidores da UFF e evitar qualquer tipo de inconveniente. Portanto, este questionário possui um total de sete questões fechadas (variáveis do estudo) de múltipla escolha, elaboradas de forma clara e objetiva. Além disso, tem por objetivo apontar os principais óbices encontrados na adoção do procedimento de cálculo da depreciação no setor público e qual o grau de adoção do procedimento de depreciação na Instituição.

Para que fosse feita a coleta dos dados, foi solicitada a Superintendência de Tecnologia da Informação (STI) a lista contendo os e-mails de todos os Técnicos de Contabilidade e Bacharéis em Contabilidade, a fim de enviar o questionário. Além disso, foi enviado, no grupo de WhatsApp dos agentes patrimoniais, o questionário, já que esses agentes participam do inventário anual dos bens permanentes que subsidia a realização anual da depreciação pela Universidade. Portanto, o universo da pesquisa foi composto de 78 servidores formados nessas áreas e 99 agentes patrimoniais, perfazendo um total de 177 profissionais desse universo.

Quanto à amostra, decidiu-se que somente os 162 servidores da ativa responderiam ao questionário, pois tiveram acesso às recentes mudanças quanto à depreciação de bens, imposta pela legislação atual. Desse total, 103 servidores responderam à pesquisa. Finalmente, para coleta dos dados foi enviado, por e-mail e WhatsApp, o questionário hospedado no Google Docs, que ficou disponível para resposta no período de 24 de junho a 08 de julho de 2019. No quadro 1 se encontra o questionário e suas variáveis.

\section{Quadro 1 - Questionário sobre depreciação em uma IFES}

\begin{tabular}{|l|l|}
\hline 1$)$ & $\begin{array}{l}\text { Você conhece a NBC TSP 07, nova norma que entrou em vigor em 01/01/2019 e estabelece o } \\
\text { tratamento contábil para ativos imobilizados? } \\
\text { ( ) Sim } \\
\text { ( ) Não }\end{array}$ \\
\hline 2) & $\begin{array}{l}\text { A Universidade Federal Fluminense adota o procedimento de depreciação de acordo com o } \\
\text { previsto na NBC TSP 07? } \\
\text { ( ) Sim } \\
\text { ( ) Não } \\
\text { ( ) Não sei }\end{array}$ \\
\hline 3$)$ & $\begin{array}{l}\text { A Instituição em que você trabalha promoveu algum tipo de treinamento para melhor atender } \\
\text { aos requisitos trazidos pela NBT TSP 07? } \\
\text { ( ) Sim } \\
\text { ( ) Não } \\
\text { ( ) Não sei }\end{array}$ \\
\hline
\end{tabular}




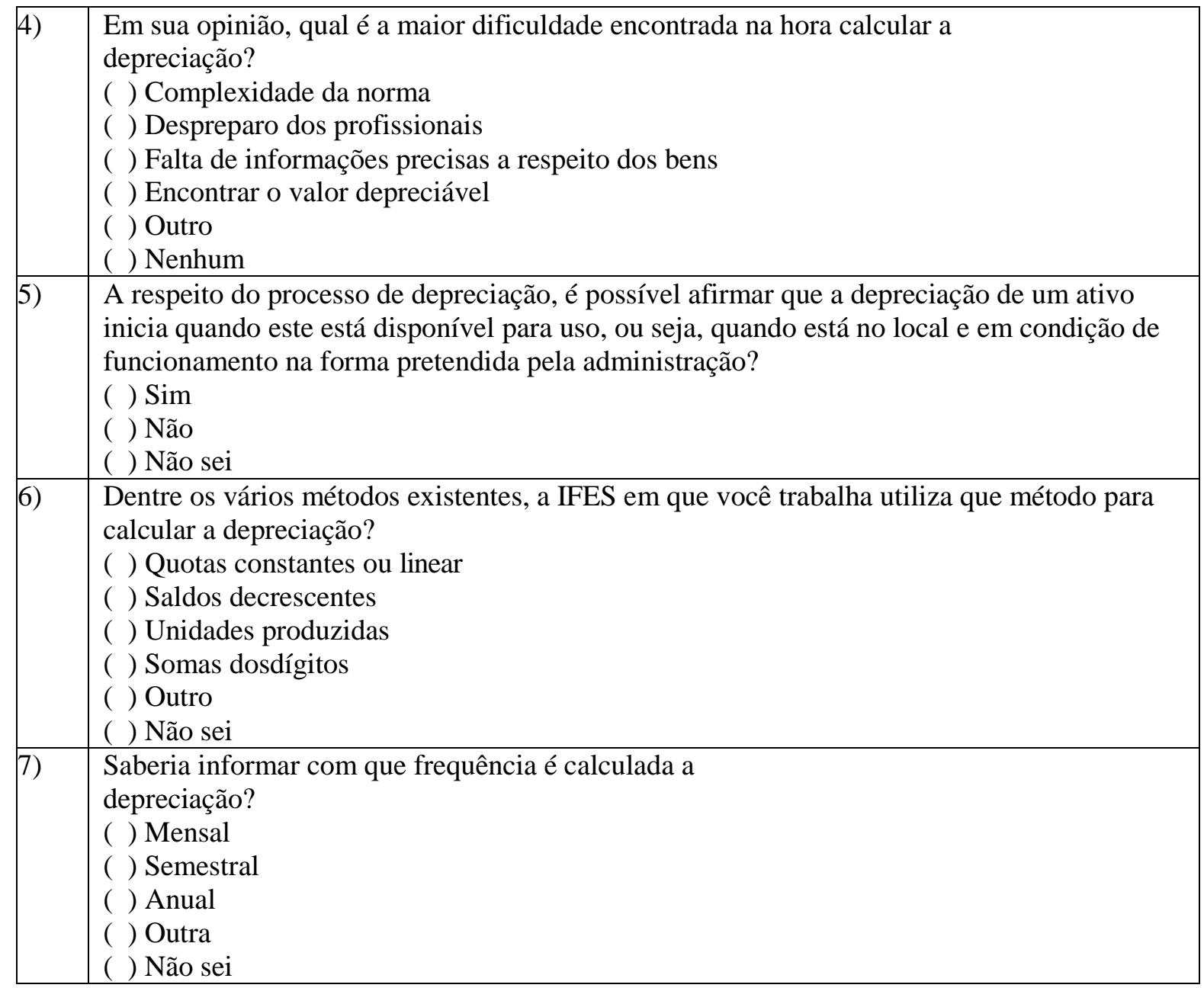

Fonte: elaborado pelos próprios autores.

Os dados da pesquisa que compõem a seção quatro foram analisados mediante análise quantitativa visando conhecer até que ponto a UFF adotou os procedimentos exigidos pela nova norma, a dificuldade dos profissionais de Contabilidade em entender e realizar o procedimento de depreciação e como está sendo realizado o cálculo da depreciação atualmente.

\section{RESULTADOS E DISCUSSÕES}

A instituição selecionada para a realização da pesquisa foi a Universidade Federal Fluminense (UFF), sediada no Estado do Rio de Janeiro, em Niterói, porém possui várias unidades espalhadas por Rio das Ostras, Macaé, Volta Redonda, Miracema, entre outras. Assim, o que levou à escolha da UFF para ser realizada a pesquisa se dá pelo fato de esta instituição ocupar a trigésima terceira posição entre as melhores Universidades da América Latina, de acordo com a Times Higher Education (2019). O segundo ponto é que os pesquisadores têm facilidade de comunicação com os servidores envolvidos na pesquisa. 
Em relação ao conhecimento dos servidores a respeito da NBC TSP 07, foi perguntado aos respondentes se eles conheciam a norma que estabelece o tratamento contábil para ativos imobilizados e que passou a vigorar em 01 de janeiro de 2019, o que está explicitado nos resultados apontados pela tabela 1 .

Tabela 1 - Conhecimento da NBC TSP 07

\begin{tabular}{|l|c|}
\hline $\begin{array}{l}\text { Você conhece a NBC TSP 07, nova norma que entrou em vigor em 01/01/2019 e estabelece o } \\
\text { tratamento contábil para ativos imobilizados? }\end{array}$ & $\%$ \\
\hline Sim & $37 \%$ \\
\hline Não & $63 \%$ \\
\hline
\end{tabular}

Fonte: elaborado pelos próprios autores.

De acordo com a tabela 1, é possível observar que a maior parte dos participantes, aproximadamente $63 \%$, não têm conhecimento da nova norma que estabelece o tratamento contábil para ativos imobilizados e que passou a ser obrigatória a partir do momento em que entrou em vigor, precisamente, 01 de janeiro de 2019.

A segunda questão foi específica sobre a adoção do procedimento de depreciação de acordo com o previsto na NBC TSP 07, cujos resultados foram apresentados na tabela 2.

Tabela 2 - A UFF e a adoção da NBC TSP 07

\begin{tabular}{|l|c|}
\hline $\begin{array}{l}\text { A Universidade Federal Fluminense adota o procedimento de depreciação de acordo com o } \\
\text { previsto na NBC TSP 07? }\end{array}$ & $\%$ \\
\hline Sim & $3,7 \%$ \\
\hline Não & $11,1 \%$ \\
\hline Não sei & $85,2 \%$ \\
\hline
\end{tabular}

Fonte: elaborado pelos próprios autores.

A segunda questão retrata um assunto importante e a maioria dos participantes, 85,2\%, não souberam informar se a UFF adota o procedimento de depreciação de acordo com a NBC TSP $07,11,1 \%$ dos participantes afirmaram que a IFES não adota o procedimento e apenas $3,7 \%$ afirmaram que sim, o que mostra que há uma dificuldade por parte da UFF em divulgar o que vem realizando nesta área.

No que diz respeito ao treinamento oferecido pela instituição em relação à NBT TSP 07, foi perguntado aos servidores se já participaram de algum treinamento referente a esta norma e os resultados foram os seguintes, conforme a tabela 3.

\section{Tabela 3 - Treinamento oferecido pela UFF}

\begin{tabular}{|l|c|}
\hline $\begin{array}{l}\text { A Instituição em que você trabalha promoveu algum tipo de treinamento para melhor atender } \\
\text { aos requisitos trazidos pela NBT TSP 07? }\end{array}$ & $\%$ \\
\hline Sim & $25,6 \%$ \\
\hline Não & $44,5 \%$ \\
\hline Não sei & $29,6 \%$ \\
\hline
\end{tabular}

Fonte: elaborado pelos próprios autores. 
Observa-se na tabela 3 a incerteza entre os participantes a respeito de treinamento promovido pela UFF, ou seja, 44,5\% afirmaram que a IFES não promoveu qualquer tipo de treinamento, 29,6\% não souberam informar e 25,9\% estão de acordo que a IFES promoveu treinamento para capacitar seus servidores. Diante desse resultado, é possível dizer que mais de $74 \%$ dos respondentes não sabem informar com precisão se houve algum tipo de capacitação que instruísse os servidores da UFF em relação às novas normas aplicadas à depreciação no setor público.

Com relação à dificuldade em se calcular a depreciação, os respondentes disseram o seguinte, conforme apresentado na tabela 4.

Tabela 4 - Dificuldade para calcular a depreciação

\begin{tabular}{|l|c|}
\hline Em sua opinião, qual é a maior dificuldade encontrada na hora calcular a depreciação? & $\%$ \\
\hline Complexidade da norma & $14,8 \%$ \\
\hline Despreparo dos profissionais & $14,8 \%$ \\
\hline Falta de informações precisas a respeito dos bens & $44,4 \%$ \\
\hline Encontrar o valor depreciável & $25,9 \%$ \\
\hline Outro & - \\
\hline Nenhum & - \\
\hline
\end{tabular}

Fonte: elaborado pelos próprios autores.

O tabela 4 evidencia a divergência entres os participantes quando se trata da dificuldade de se calcular a depreciação. Mais da metade dos participantes, aproximadamente 70,3\%, optaram por falta de informações precisas a respeito dos bens e encontrar o valor depreciável. Outros $14,8 \%$ acreditam que os profissionais estejam despreparados e outros $14,8 \%$ entendem que a complexidade da norma dificulta sua aplicação.

Em relação ao início do processo de depreciação, foi perguntado aos servidores se sabiam quando a depreciação se inicia. $\mathrm{O}$ resultado pode ser visto no tabela 5.

\section{Tabela 5 - Início do processo de depreciação}

\begin{tabular}{|l|c|}
\hline $\begin{array}{l}\text { A respeito do processo de depreciação, é possível afirmar que a depreciação de um ativo inicia } \\
\text { quando este está disponível para uso, ou seja, quando está no local e em condição de } \\
\text { funcionamento na forma pretendida pela administração? }\end{array}$ \\
\hline Sim & $81 \%$ \\
\hline Não & - \\
\hline Não sei & $19 \%$ \\
\hline
\end{tabular}

Fonte: elaborado pelos próprios autores.

Quanto à questão que trata do início do processo de depreciação, tal como estabelecido pela NBC TSP 07, 81,5\% dos participantes estão alinhados com a determinação da norma. 
Enquanto 18,5\% dos participantes não souberam responder se o enunciado não está de acordo com o descrito na norma.

Ainda sobre a depreciação, foi questionado sobre qual método a UFF adota para calcular a depreciação, o que pode ser visto na tabela 6 .

Tabela 6 - Método adotado pela UFF

\begin{tabular}{|l|c|}
\hline Em sua opinião, qual é a maior dificuldade encontrada na hora calcular a depreciação? & $\%$ \\
\hline Quotas constantes ou linear & $55,6 \%$ \\
\hline Saldos decrescentes & - \\
\hline Unidades produzidas & - \\
\hline Somas dos dígitos & - \\
\hline Outro & - \\
\hline Não sei & $44,4 \%$ \\
\hline
\end{tabular}

Fonte: elaborado pelos próprios autores.

A norma determina que o método das quotas constantes, saldos decrescentes e unidades produzidas podem ser aplicados sem prejuízo. Portanto, essa questão deixou claro que grande parte dos participantes, 44,4\%, não sabem qual o método que a UFF adota para calcular a depreciação dos seus bens, enquanto 55,6\% afirmaram ser o método das quotas constantes adotado pela IFES. O método das quotas constantes é o mais simples de ser aplicado e analisado, pois calcula a depreciação com base na vida útil, por isso acredita-se que foi o mais citado como resposta.

Com relação à periodicidade da depreciação, os respondentes informaram o seguinte, conforme o tabela 7.

Tabela 7 - Periodicidade do cálculo da depreciação

\begin{tabular}{|l|c|}
\hline Saberia informar com que frequência é calculada a depreciação? & $\%$ \\
\hline Mensal & $66,7 \%$ \\
\hline Semestral & - \\
\hline Anual & - \\
\hline Outra & - \\
\hline Não sei & $33,3 \%$ \\
\hline
\end{tabular}

Fonte: elaborado pelos próprios autores.

Quanto à periodicidade, a maioria dos participantes, precisamente 66,7\%, marcaram que a depreciação é calculada de forma mensal, enquanto 33,3\% não sabem com que frequência a depreciação é calculada. Segundo a norma, a apuração da depreciação deve ser mensal quando o ativo estiver em condição de uso e que a depreciação deve ser feita até que o seu valor líquido contábil seja igual ao valor residual. 


\section{CONSIDERAÇÕES FINAIS}

A depreciação aplicada ao setor público é de suma importância para qualquer entidade, pois por meio dela é possível visualizar a forma como os ativos imobilizados estão tratados e onde estão sendo empregados de acordo com a sua finalidade, tornado o processo mais transparente.

Este artigo teve como objetivo verificar e analisar o grau de adoção do procedimento de depreciação na Universidade Federal Fluminense (UFF), sediada no Estado do Rio de Janeiro. Para tal, foram demonstradas a relevância e as características da depreciação no setor público e, por meio do questionário aplicado, foi possível apontar os principais óbices encontrados na adoção do procedimento de cálculo da depreciação neste setor.

Portanto, conforme as respostas apuradas pelo questionário aplicado, ficou claro que a maior parte dos participantes não tem conhecimento da nova norma que trata da depreciação, a NBC TSP 07, ou seja, 63\% não conhecem a referida norma. Além disso, foi possível notar que de acordo com grande parte dos respondentes, precisamente 44,4\%, a IFES não promoveu nenhum tipo de treinamento para melhor qualificar seus servidores, enquanto 29,6\% não sabiam e outros $25,9 \%$ disseram que sabiam. Ainda sobre o questionário, ficou evidente que quando se trata da dificuldade de calcular a depreciação a maioria dos participantes afirmou que a falta de informações precisas a respeito dos bens e encontrar o valor depreciável estão entre os maiores problemas.

Desse modo, o problema de pesquisa, ou seja, até que ponto o procedimento de depreciação, conforme previsto pela NBC TSP 07, tem sido aplicado pela Universidade Federal Fluminense (UFF), pode ser respondido da seguinte maneira: a maioria dos respondentes, $82,5 \%$, não souberam responder em que grau está sendo adotado o procedimento de depreciação de acordo com o que a NBC TSP 07 prevê.

Sendo assim, por tudo o que foi dito e de acordo com o que os servidores responderam, a IFES estudada, quanto ao assunto depreciação, é preciso mais observância às normas e legislação. Para prestar um melhor serviço de controle, qualidade e transparência, é preciso que se invista em softwares capazes de armazenar e disponibilizar informações a respeito dos ativos imobilizados e compartilhar essas informações para todos os setores da Universidade que trabalham direta ou indiretamente com depreciação, promover eventos e treinamentos para capacitar os servidores sempre que novas normas forem editadas pelo CFC e órgãos reguladores e adotar integralmente as normas exigidas pela legislação, para que a informação contábil esteja sempre padronizada e transparente para todos os setores da sociedade. 
Por fim, futuramente, em novas pesquisas, recomendam-se estudos mais aprofundados a respeito da depreciação no setor público, pois o assunto é pouco explorado nas universidades brasileiras e se trata de uma norma nova, para que se possa então desenvolver com maior clareza e especificidade um comparativo das decisões das gestões e os impactos de tais processos na informação e na gestão destas instituições.

\section{REFERÊNCIAS}

- Ministério da Fazenda. Secretaria do Tesouro Nacional. Manual de Contabilidade Aplicado ao Setor Público. $8^{\mathrm{a}}$ ed. Disponível em https://www.cnm.org.br. Acesso em 09 de junho de 2019.

. Norma Brasileira de Contabilidade, NBC TSP 07, de 22 de setembro de 2017. http://www1.cfc.org.br/sisweb/SRE/docs/NBCTSP07.pdf. Acesso em 10 de junho de 2019.

. Portaria $\mathbf{n}^{\mathbf{0}}$ 184, de 25 de agosto de 2008. Dispõe sobre as diretrizes a serem observadas no setor público quanto aos procedimentos, práticas, elaboração e divulgação das demonstrações contábeis, de forma a torná-los convergentes com as Normas Internacionais de Contabilidade Aplicadas ao Setor Público. Disponível em: http://www.fazenda.gov.br/acessoa-informacao/institucional/legislacao/portarias-ministeriais/2008/portaria184. Acesso em 25 de maio de 2019.

BEZERRA FILHO, J. E. Contabilidade Pública: Teoria, técnica de elaboração de Balanços e 500 questões. 2. ed. Rio de Janeiro: Elsevier, 2006.

BRASIL. Lei $n^{\mathbf{0}}$ 10.406, de 10 de janeiro de 2002. Institui o Código Civil Brasileiro. Disponível em: http://www.planalto.gov.br/ccivil_03/leis/2002/110406.htm. Acesso em $10 \mathrm{de}$ junho de 2019.

CARVALHO, D.; CECCATO, M. Manual completo de contabilidade pública. Rio de Janeiro: Elsevier, 2011.

CONSELHO FEDERAL DE CONTABILIDADE. Resolução CFC no 1.128 a 1.137, de 21 de novembro de 2008. Disponível em http://portalcfc.org.br/wordpress/wpcontent/uploads/2013/11/setor_publico.pdf. Acesso em 27 maio 2019.

CONSELHO FEDERAL DE CONTABILIDADE. Resolução CFC $\mathbf{n}^{\mathbf{0}} \mathbf{1 1 3 6}$, de 25 de novembro de 2008. Disponível em: http://www1.cfc.org.br/sisweb/SRE/docs/RES_1136.pdf. Acesso em 09 de junho de 2019.

COSTA, C. L. O.; CUNHA, D. O.; BEZERRA, L. F.; OLIVEIRA, F. L.; VALE JÚNIOR, J. S.; SEVERIANO JUNIOR, E. The corruption in the brazilian public sector. Research, Society and Development, v. 9, n. 10, p. e5939109056, 2020a. 
COSTA, C. L; CUNHA, O. D.; SEVERIANO JÚNIOR, E.; VALE JÚNIOR, J. S.; GOMES, J. S. O Controle Interno Atua de Acordo com A Legislação? Estudo de Caso da Prefeitura Municipal de Sabará. Rev. FSA, Teresina, v.17, n. 12, art. 5, p. 96-117, dez. 2020b.

CUNHA, D. O.; SEVERIANO JUNIOR, E. O Uso do Tratamento de Esgoto Sustentável: O Estado da Arte das Wetlands. Revista de Tecnologia Aplicada, v. 7, n. 3, p. 20-35, 2018.

IUDÍCIBUS, Sergio de et al. Equipe de professores da FEA/USP S. Contabilidade Introdutória. 11. ed. São Paulo: Atlas, 2010.

IUDÍCIBUS, Sergio de et al. Equipe de professores da FEA/USP S. Teoria da Contabilidade. 4. ed. São Paulo: Atlas, 1995.

IUDÍCIBUS, Sergio de et al. Manual de Contabilidade Societária: aplicável a todas as sociedades de acordo com as normas internacionais e do CPC. 1. Ed. São Paulo: Atlas, 2010.

MARION, J. C. Contabilidade Básica. São Paulo: Atlas, 1988.

MOTA, F. G. L. Contabilidade Aplicada ao Setor Público. 1. ed. Brasília: Coleção Gestão Pública, 2009.

ROSA, M. B. Contabilidade do Setor Público. São Paulo: Atlas, 2011.

SILVA, J. A. F. Contabilidade Pública. 1ª ed. Rio de Janeiro: Elsevier, 2014.

SOUZA, S. A. Contabilidade gerai 3D: básica, intermediária e avançada. 3. ed. rev. e atual. Salvador: Juspodivm, 2016.

\section{Como Referenciar este Artigo, conforme ABNT:}

COSTA, C. L. O; CUNHA, D. O; COSTA, G. A. O; PINTO, C. A. S; GONÇALVES, C. P; A Nova Contabilidade Pública Brasileira e Sua Aplicação em uma Instituição Federal de Ensino Superior do Rio de Janeiro. Rev. FSA, Teresina, v.18, n. 6, art. 4, p. 77-95, jun. 2021.

\begin{tabular}{|l|c|c|c|c|c|}
\hline \multicolumn{1}{|c|}{ Contribuição dos Autores } & $\begin{array}{c}\text { C. L. O. } \\
\text { Costa }\end{array}$ & $\begin{array}{c}\text { D. O. } \\
\text { Cunha }\end{array}$ & $\begin{array}{c}\text { G. A. O. } \\
\text { Costa }\end{array}$ & $\begin{array}{c}\text { C. A. S. } \\
\text { Pinto }\end{array}$ & $\begin{array}{c}\text { C. P. } \\
\text { Gonçalves }\end{array}$ \\
\hline 1) concepção e planejamento. & $\mathrm{X}$ & $\mathrm{X}$ & $\mathrm{X}$ & & \\
\hline 2) análise e interpretação dos dados. & $\mathrm{X}$ & $\mathrm{X}$ & $\mathrm{X}$ & & \\
\hline 3) elaboração do rascunho ou na revisão crítica do conteúdo. & $\mathrm{X}$ & $\mathrm{X}$ & $\mathrm{X}$ & $\mathrm{X}$ & $\mathrm{X}$ \\
\hline 4) participação na aprovação da versão final do manuscrito. & $\mathrm{X}$ & $\mathrm{X}$ & $\mathrm{X}$ & $\mathrm{X}$ & $\mathrm{X}$ \\
\hline
\end{tabular}

